\title{
Evaluation for Innovation Ability of National Agricultural Science and Technology Parks in Jiangxi Province
}

\author{
Jun Yang1,2, Ling Lin ${ }^{3}$, Can Huang2, Xin Feng ${ }^{4}$ \\ ${ }^{1}$ School of Statistics, Jiangxi University of Finance and Economics, Nanchang, China \\ ${ }^{2}$ Nanchang Business College of Jiangxi Agricultural University, Nanchang, China \\ ${ }^{3}$ School of Foreign Languages, Jiangxi Agricultural University, Nanchang, China \\ ${ }^{4}$ Modern Economics \& Management College, Jiangxi University of Finance and Economics, Nanchang, China \\ Email: *jxufewyd@163.com
}

How to cite this paper: Yang, J., Lin, L., Huang, C. and Feng, X. (2018) Evaluation for Innovation Ability of National Agricultural Science and Technology Parks in Jiangxi Province. American Journal of Plant Sciences, 9, 2446-2461.

https://doi.org/10.4236/ajps.2018.912177

Received: October 26, 2018

Accepted: November 23, 2018

Published: November 26, 2018

Copyright $\odot 2018$ by authors and Scientific Research Publishing Inc. This work is licensed under the Creative Commons Attribution International License (CC BY 4.0).

http://creativecommons.org/licenses/by/4.0/

\begin{abstract}
Innovative ability is an important indicator for judging the effectiveness of the national agricultural science and technology park construction. Based on the statistical data of four national agricultural science and technology parks built in Jiangxi Province, this paper constructs an evaluation system consisting of three first-level indicators, eight second-level indicators and 24 three-level indicators. Based on the combined weighting method, the comprehensive scores of the innovation capabilities of the parks are obtained. It is found that the gap in innovation capability of each park is wide, and the radiation-driven function has not yet appeared. It is necessary to promote the improvement of innovation capabilities by promoting the synergy and innovation of agricultural science and technology in the park, encouraging the park to construct agricultural technology business incubators, and building and improving innovation platforms.
\end{abstract}

\section{Keywords}

National Agricultural Science and Technology Park, Innovation Ability, Evaluation Index System

\section{Introduction}

In the 1990s, agricultural production in the developed countries of the world has basically achieved high technology. As a large agricultural country, China is in the transition stage from traditional agriculture to modern agriculture. Agricultural development puts forward higher requirements for the diffusion and ap- 
plication of agricultural innovation technology, while the traditional agricultural science and technology extension system has been difficult to meet the farmers' strong demand for new technologies and new varieties in actual production. Agricultural science and technology parks emerged as a new type of organization form for agricultural technology innovation and transformation of agricultural science and technology achievements.

At the National Agricultural Science and Technology Conference in 2001, the Party Central Committee and the State Council listed the construction of the National Agricultural Science and Technology Park as an important action of science and technology. After more than 10 years of pilot construction and comprehensive advancement, by the end of 2017, China has approved the establishment of 246 parks, covering all provinces, autonomous regions, municipalities directly under the Central Government, cities with separate plans, and Xinjiang Production and Construction Corps. The overall development pattern of distinctive features, typical models, and significant demonstration of science and technology is formed [1].

General Secretary Xi Jinping said: "Give the wings of science and technology to agriculture." The Agricultural Science and Technology Park plays a very important role in promoting the adjustment of agricultural structure, cultivating leading industries, improving the technological innovation capability of agricultural enterprises, and increasing farmers' income. Jiangxi has a large agricultural population and a wide rural area. Agricultural products such as grain, pigs and oil occupy an important position in the country. It is an important agricultural product supply base for the Yangtze River Delta and the Pearl River Delta. Jiangxi province has been actively promoting the construction of agricultural science and technology parks. By the end of 2014, Jiangxi province has built four national agricultural science and technology parks (NASTP) in Nanchang, Jing gangshan, Xinyu and Shangrao. The four parks realized a total output value of 4.277 billion RMB for the first, second and third industry, and 193 agricultural enterprises settled in the park, driving 157,000 local farmers to find employment [2]. In 2015, Jiangxi Province was awarded three NASTP in Fengcheng, Ganzhou and Pingxiang. The scale of the park has gradually grown. The National Agricultural Science and Technology Park has become an important platform for independent innovation and transformation of agricultural science and technology, become an important base for innovation and entrepreneurship in rural areas. It has also become the cradle of cultivating and stimulating new forms and models of business in the agricultural industry, driving a powerful engine for economic growth [3].

The current innovation-driven development strategy and rural revitalization strategy have put forward new requirements and opportunities for the construction and development of NASTP. What are the differences in the innovation capabilities of each national agricultural science and technology park in Jiangxi province, and what kind of path should be taken to improve the innovation abil- 
ity of the park? The study of these problems is of great significance to the coordinated development of agricultural science and technology construction and rural economy in Jiangxi Province, and has important reference value for the construction of other parks.

\section{Literature Review}

Domestic scholars' research on NASTP mainly focuses on development models, park planning and construction. For example, Jiang Heping and Cui Kai (2009) summarized the modes in the construction of agricultural science and technology parks and proposed four radiation-driven forms. They believed that agricultural science and technology parks effectively promoted the transformation, demonstration and application of agricultural scientific and technological achievements, and promoted the adjustment and upgrading of agricultural industry structure [4]. Zhang Changhai (2012) conducted a research on the comprehensive development model of modern agricultural science and technology parks for agricultural scientific research units integrating scientific and technological innovation, production demonstration, technology promotion, popular science education, sightseeing and tourism, and commercial trade [5]. Sun Hongyong et al. (2016) studied the organizational development model of government guidance, association participation and enterprise (farmers) as the main body, and the three-level parallel technology operation development model with farmers professional cooperatives, family farms and technology demonstration households as the main body, and spatial layout pattern of core area, demonstration area and radiation area in circle layout mode [6]. Shao Hua (2012) took Shandong Binzhou National Agricultural Science and Technology Park as an example to explore and study the planning problems of national agricultural science and technology parks [7]. Zhou Jian et al. (2016) believe that although the agricultural science and technology parks in Xinyu have achieved some achievements, there are still bottlenecks such as insufficient talents, insufficient funds, and insufficient linkage mechanism with farmers' interests, which makes the innovation cluster effect of the park not obvious, and the economic benefits need to be improved [8].

Some scholars have also analyzed the effects of the National Agricultural Science and Technology Park from different perspectives. He Wei (2007) used the $C^{2} \mathrm{R}$ model in DEA to sort the agricultural science and technology parks through the benefit status, and obtained the current situation of the scale benefit of each park and proposed the path of optimizing the input of factors [9]. Zhao Liming et al. (2014) used the CES model to estimate the industrial agglomeration effect of the Xuchang National Agricultural Science and Technology Park in Henan Province [10]. Xu Chenqing et al. (2016) used the statistical data of 2013 to screen out 28 NASTP, using data envelopment analysis methods to measure their total efficiency, technical efficiency and scale efficiency [11].

In recent years, more and more scholars have studied the NASTP from the 
perspective of functional orientation. Shen Xiuqing et al. (2012) believe that China's agricultural science and technology parks have the functions of technology integration, industry incubation and technology demonstration [12]. Song Yanping (2018) used the statistical data of 69 NASTP as a sample, based on the factor analysis method to establish a model for evaluating the radiation-driven capacity of the National Agricultural Science and Technology Park, and finally obtained the comprehensive scores and rankings of various agricultural science and technology parks, which providing a reference for promoting the development of each park [13]. Zhou Huaqiang et al. (2018) built an evaluation index system based on the three functions of innovation leading, entrepreneurship incubation and demonstration driving in agricultural science and technology parks, and drew conclusions [14].

However, from the perspective of innovation capability, there is relatively little literature on constructing an evaluation index system for the innovation capability of NASTP Henry Etzkowitz (2004) pioneered a new paradigm for innovative research. He proposed a three-helix theory of innovation and development in the park. Specifically, the park is based on universities, industry and government, and presents spiral development for the purpose of resource integration, so it is called "three-helix theory". In the triple helix theory, universities and scientific research institutions are regarded as the main assets of the park for the first time [15]. Xu Yuexian (2004) based on the theory of integrated innovation, concluded that if the agricultural science and technology park adopts the integrated innovation model, it can effectively promote the development of the park and regional agriculture [16]. Zhou Lijun (2010) believes that the innovation capability of the park is mainly composed of the knowledge creation, the study of economic subjects and social capital in the park [17]. Luo Guangning et al. (2016) used the description method to evaluate the innovation ability of the NASTP in Guangdong from three dimensions: innovation level, innovation support and innovation performance, but it was only a simple statistical analysis. There was neither an index system nor an evaluation model for conducting empirical research [18]. Xia Yanlei et al. (2017) constructed an index system and evaluated the innovation ability of Anhui Agricultural Science and Technology Park based on AHP [19]. In each comprehensive evaluation model, in order to determine the weight coefficient of each evaluation index, the evaluation results should be comprehensively considered from both qualitative and quantitative research.

Before 2014, Jiangxi Province approved a total of four NASTP. Specifically, it includes the second batch of Nanchang and Jinggangshan National Agricultural Science and Technology Park approved in 2002, the third batch of Xinyu National Agricultural Science and Technology Park approved in 2010, and the fifth batch of Shangrao National Agricultural Science and Technology Park approved in 2013. In February 2015, the sixth batch of three new NASTP were added, namely Ganzhou, Fengcheng and Pingxiang national agricultural science and 
technology parks. The seventh batch of Yichun National Agricultural Science and Technology Park was added in December 2015. Since the NASTP approved after 2015 have not obtained corresponding data for various reasons, this paper takes the four NASTP before 2014 as an example for analysis.

From the "National Key Park Innovation Monitoring Report (2016)" published by the Ministry of Science and Technology in 2017, it can be seen that the four major parks in Jiangxi Province have continuously increased capital investment by integrating government, enterprises and various social resources. By building innovation carriers such as R \& D center and e-commerce platform for agricultural products, they gather capital, technology and talents to enhance the innovation capacity of the parks. In 2016, the total investment and financing of the four major parks in Jiangxi Province reached 2.354 billion RMB, of which the annual R \& D investment was 54.053 million RMB, and the financial, corporate and social financing ratios were $6.07 \%, 73.87 \%$ and $20.05 \%$ respectively. The enterprise investment in the four parks all exceeds the government input, indicating that the enterprise capital investment is the main source of funds in the parks.

By the end of 2016, the total number of R \& D centers in the core areas of the four NASTP in Jiangxi Province was 51, of which 12 were R \& D centers above the provincial level, accounting for $23.53 \%$ of the total number of $\mathrm{R} \& \mathrm{D}$ Centers in the park [20]. The number of R \& D centers in Shangrao Park is the largest, with 24, which is significantly faster than that in 2014 . The proportion of R \& D personnel in different parks varies greatly. The proportion of $\mathrm{R} \& \mathrm{D}$ personnel from high to low is Nanchang, Jing Gangshan and Xinyu. The proportion of R \& D personnel in Nanchang Park is $54.46 \%$, and the lowest in Shangrao Park is only $6.58 \%$.The science and technology commissioners have played an important role in entrepreneurship innovation, significantly improving the level of agricultural science and technology in the park. There are 112 science and technology commissioners and 28 science and technology development projects in the park. The total investment of the project is 138.4 million RMB, the annual profit is 63.71 million RMB, and 19 enterprises are established, which is doubled compared with 2014. The increase in human, financial and material resources of the national Agricultural Science and Technology Park of Jiangxi province has provided the necessary foundation and support for the improvement of innovation capacity.

The National Agricultural Science and Technology Park has adopted the modes of "company + farmer" model to drive and guide farmers in the surrounding areas to apply new agricultural technological achievements, effectively improving the technical level in agricultural production and promoting the increase of farmers' income. In 2016, the four major parks in Jiangxi Province achieved 3.422 billion RMB in business revenue, 513.8 million RMB in export tax revenue, the average annual net profit of each park was 73.21 million RMB, with which the total amount of tax paid was 40.75 million RMB. There are a total 
of 12,000 employees in the park, and the number of local farmers is 38,582 [20]. The strongest employment-driven capacity is Shangrao Park and Nanchang Park, which respectively promoted 145.8 million and 12,200 local farmer. The annual per capita income of the employee in the park is $145,856 \mathrm{RMB}$. The highest per capita income of the employees is Jing Gangshan Park and Shangrao Park, which are 50,000 RMB and 35,700 RMB respectively. The annual per capita net income of farmers in the park is $72,462 \mathrm{RMB}$, which is $13,927 \mathrm{RMB}$ higher than that of the local farmers. The highest per capita net income of the farmers in the park is Jing Gangshan Park and Xinyu Park, which are 38,000 RMB and $15,000 \mathrm{RMB}$ respectively; which has greatly increased the income of local farmers.

In summary, the innovation investment of the NASTP in Jiangxi Province has been continuously increased, and the ways of innovation have become increasingly abundant. The innovation capability has been enhanced constantly, and the integration demonstration and radiation-driven benefits have been continuously improved. However, the problems in the imbalance of scientific and technological innovation were more prominent, and the gap of innovation level between the parks has become larger and larger. Among them, Nanchang and Jing Gangshan Parks show a high level of innovation capability, however annual per capita net income of farmers in Shangrao Park is far lower than local farmers. It is related to many factors such as construction time, construction foundation and policy environment of the four parks. Therefore, based on the analysis of the status quo and characteristics of science and technology innovation in Jiangxi National Agricultural Science and Technology Park of Province, this paper constructed an index system of innovation capability, mainly using the subjective and objective combination weighting method to measure the difference of innovation ability between parks. Finally, the corresponding strategy is proposed which is based on the calculation results.

\section{Evaluation of Innovation Capacity of National Agricultural Science and Technology Park in Jiangxi Province}

\subsection{Evaluation Index System of the NASTP Innovation Capability}

In 2014, the Rural Department of the Ministry of Science and Technology combed the constituent elements and indicators of the innovation capability of the agricultural science and technology park, and established a monitoring index system covering the three aspects of the innovation output, innovation conditions and innovation performance of the agricultural science and technology park. Based on the local characteristics and expert opinions of Jiangxi Province, this paper screens out the indicators of the ability to focus on innovation, and builds an evaluation index system from the aspects of innovation support, innovation level and innovation performance. The system includes three first-level indicators, eight second-level indicators, and 24 third-level indicators (as shown in Table 1). 
Table 1. Evaluation model of national agricultural science and technology park innovation capability.

\begin{tabular}{|c|c|c|}
\hline Primary indicator & Secondary indicator & Three-level indicator \\
\hline \multirow{11}{*}{$\begin{array}{l}\text { Innovation support } \\
\qquad(\mathrm{A} 1)\end{array}$} & & C1 Number of science and technology commissioners (person) \\
\hline & $\begin{array}{c}\text { Human } \\
(\mathrm{B} 11)\end{array}$ & C2 Number of R \& D personnel (person) \\
\hline & & C3 Number of resident experts (person) \\
\hline & & C4 Annual total investment and financing of the park (100 million RMB) \\
\hline & $\begin{array}{l}\text { financial resources } \\
\qquad(\mathrm{B} 12)\end{array}$ & C5 The proportion of enterprise R \& D total investment in main business income (\%) \\
\hline & & C6 The original value of large instruments and equipment (ten thousand RMB) \\
\hline & & $\begin{array}{l}\text { C7 The number of } \mathrm{R} \& \mathrm{D} \text { centers at or above the provincial level accounts for a proportion } \\
\text { of the total number of } \mathrm{R} \& \mathrm{D} \text { centers in the park }(\%)\end{array}$ \\
\hline & $\begin{array}{l}\text { Material power } \\
\text { (B13) }\end{array}$ & C8 Informatization investment (ten thousand RMB) \\
\hline & & C9 Number of e-commerce platforms (PCS) \\
\hline & & $\mathrm{C} 10$ the number of patents granted, (PCS) \\
\hline & & C11 The Number of intellectual property acquired in the year (PCS) \\
\hline \multirow{6}{*}{$\begin{array}{l}\text { Level of innovation } \\
\qquad(\mathrm{A} 2)\end{array}$} & $\begin{array}{l}\text { R \& D capabilities } \\
\quad(B 21)\end{array}$ & $\begin{array}{l}\text { C12 The number of new varieties of plants, animals, birds and aquatic products approved at } \\
\text { or above the provincial level (PCS) }\end{array}$ \\
\hline & & C13 Introduction of new technology, new products, new facilities (PCS) \\
\hline & Development capability & C14 Introduction of new species of plants, livestock and aquatic products (PCS) \\
\hline & (B22) & C15 Promotion of new technology, new products, new facilities (PCS) \\
\hline & Promotion ability & C16 Popularizing new varieties of plants, animals, birds and aquatic products (PCS) \\
\hline & $(\mathrm{B} 23)$ & C17 Annual net profit (10,000 RMB) \\
\hline \multirow{7}{*}{$\begin{array}{l}\text { Innovation performance } \\
\qquad(\mathrm{A} 3)\end{array}$} & & $\begin{array}{l}\mathrm{C} 18 \text { The ratio of technical income and sales of production materials to annual gross output } \\
\text { value (\%) }\end{array}$ \\
\hline & $\begin{array}{l}\text { Economic effects } \\
\quad(\text { B31) }\end{array}$ & $\begin{array}{l}\text { C19 The output value of the secondary and tertiary industries accounts for the proportion of } \\
\text { total output value (\%) }\end{array}$ \\
\hline & & C20 Annual per capita net income of farmers in the park (RMB) \\
\hline & & C21 Annual number of visitors (person) \\
\hline & & C22 Total annual training (person) \\
\hline & Social effect (B32) & C23 Number of innovative brands (PCS) \\
\hline & & C24 Incubate the number of graduate enterprises (PCS) \\
\hline
\end{tabular}

Among them, the innovative support has set up three secondary indicators to measure the innovation investment of the park in human, financial and material aspects. The level of innovation has set up three secondary indicators, focusing on the knowledge creation, knowledge radiation and technical level of the park. Innovative performance sets two secondary indicators to evaluate the economic and social benefits of the park.

\subsection{National Agricultural Science and Technology Park Innovation Capability Evaluation Model}

In the comprehensive evaluation model, the most important question is which 
weight method is chosen to determine the weight coefficient of each indicator. Different weight methods will lead to inconsistency in the evaluation results. Up to now, with the deepening of theoretical and methodological research, scholars have made many achievements in the research on the determination of index weight. At present, there are generally three methods for determining the weight coefficient: subjective weighting method, objective weighting method and combined weighting method. The subjective weighting method is a method of determining the weights by experts. The weighting coefficient is determined according to the judgment of the decision makers or experts on the subjective importance of each index attribute. At present, the subjective weighting methods commonly used in the theoretical circle include the expert survey (Delphi method), the factor-paired comparison method, the analytic hierarchy process (AHP), the binomial coefficient method, and sequential grading method, etc. However, according to the subjective weighting method attribute itself to determine the weight, its objectivity is necessarily poor.

In order to eliminate the influence of expert subjectivity on the evaluation results, the academic community put forward the concept of objective weighting method. Commonly used objective weighting methods are as follows: factor analysis, entropy method, dispersion and mean square error method, coefficient of variation method, CRITIC method, etc. However, the objective weighting method fails to take into account the actual meaning of the attribute, which cannot reflect the degree of importance that decision makers attach to different attributes. Sometimes the determined weight is contrary to the actual importance of attribute. Considering the advantages and disadvantages of these two methods of weighting, this paper adopts the combined weighting method which based on AHP and entropy method. The results will be more authentic and reliable. The specific steps are as follows:

First, according to the degree of influence of various indicators on the innovation ability of agricultural science and technology parks and the evaluation criteria of research experts, the three-level scales, which proposed by Professor Thomas L. Saaty are compared and analyzed to construct a judgment matrix. The calculation of the weight value is illustrated by taking the primary index as an example. The calculation method of the second-level index and the third-level index is the same, and will not be described. First, the elements of the primary indicator A are now normalized by column to obtain a matrix $Q=\left(q_{i j}\right)_{n \times n}$, among them, $q_{i j}=a_{i j} / \sum_{k=1}^{n} a_{i j}$. Add the elements of $Q$ in rows to get the vector $\alpha=\alpha\left(\alpha_{1}, \alpha_{2}, \cdots, \alpha_{n}\right)$, among them, $\alpha_{i}=\sum_{k=1}^{n} \alpha_{k}$. Then find the maximum eigenvalue $\lambda_{\max }=\frac{1}{n} \sum_{i=1}^{n} \frac{(A W)_{i}}{w_{i}}$. According to the obtained $\lambda_{\max }, C I=\frac{\lambda_{\max }-n}{n-i}$ can be obtained. With the help of the look-up table to get the $R I$ value, we can obtain the value of $\frac{C I}{R I}$. When $\frac{C I}{R I}<0.1$, it means that the constructed matrix has 
consistency; otherwise, it means that there is no consistency, which it needs to be recalculated to get a new judgment matrix. According to the analytic hierarchy process (AHP), the weights of the indicators in the total are obtained, as shown in the fourth column of Table 2.

Second, in order to remove the influence of the dimension, the data is unified and normalized before the calculation of the entropy value is performed, we can get $X_{i j}^{\prime}$. Then the proportion $p_{i j}$ of project I under the J-TH index was calculated, among them $p_{i j}=X_{i j}^{\prime} / \sum_{i=1}^{n} X_{i j}^{\prime}$. Then calculate the entropy of the J-TH

Table 2. Estimation results of the park's innovation capability.

\begin{tabular}{|c|c|c|c|c|c|}
\hline \multirow{2}{*}{$\begin{array}{l}\text { Primary } \\
\text { indicator }\end{array}$} & \multirow{2}{*}{$\begin{array}{l}\text { Secondary } \\
\text { indicator }\end{array}$} & \multirow{2}{*}{$\begin{array}{l}\text { Three-level } \\
\text { indicator }\end{array}$} & \multicolumn{3}{|c|}{ Partial weight } \\
\hline & & & $\begin{array}{c}\text { Subjective } \\
\text { weight }\end{array}$ & $\begin{array}{l}\text { Objective } \\
\text { weight }\end{array}$ & $\begin{array}{c}\text { Combination } \\
\text { weight }\end{array}$ \\
\hline \multirow{9}{*}{$\begin{array}{c}\text { Innovation } \\
\text { support } \\
(\mathrm{A} 1,0.34)\end{array}$} & \multirow{6}{*}{$\begin{array}{c}\text { financial resources } \\
(\mathrm{B} 12,0.163)\end{array}$} & $\mathrm{C} 1$ & 0.02 & 0.0433 & 0.0316 \\
\hline & & $\mathrm{C} 2$ & 0.028 & 0.0435 & 0.0357 \\
\hline & & C3 & 0.022 & 0.0434 & 0.0327 \\
\hline & & $\mathrm{C} 4$ & 0.071 & 0.0286 & 0.0498 \\
\hline & & C5 & 0.055 & 0.025 & 0.04 \\
\hline & & C6 & 0.04 & 0.0365 & 0.0382 \\
\hline & \multirow{3}{*}{$(\mathrm{B} 1,0.0413$} & C7 & 0.064 & 0.0306 & 0.0473 \\
\hline & & $\mathrm{C} 8$ & 0.019 & 0.0233 & 0.0211 \\
\hline & & C9 & 0.027 & 0.0242 & 0.0256 \\
\hline \multirow{7}{*}{$\begin{array}{c}\text { Level of } \\
\text { innovation } \\
(\mathrm{A} 2,0.16)\end{array}$} & \multirow{3}{*}{$\begin{array}{c}\text { R \& D } \\
\text { capabilities } \\
(\mathrm{B} 21,0.166)\end{array}$} & $\mathrm{C} 10$ & 0.099 & 0.0402 & 0.0696 \\
\hline & & $\mathrm{C} 11$ & 0.1 & 0.0519 & 0.0759 \\
\hline & & $\mathrm{C} 12$ & 0.006 & 0.0953 & 0.0507 \\
\hline & \multirow{2}{*}{$\begin{array}{c}\text { Development } \\
\text { capability } \\
(\mathrm{B} 22,0.089)\end{array}$} & $\mathrm{C} 13$ & 0.022 & 0.0382 & 0.0301 \\
\hline & & $\mathrm{C} 14$ & 0.026 & 0.0331 & 0.0296 \\
\hline & \multirow{2}{*}{$\begin{array}{l}\text { Promotion ability } \\
\text { (B23, 0.048) }\end{array}$} & C15 & 0.021 & 0.0203 & 0.0206 \\
\hline & & $\mathrm{C} 16$ & 0.022 & 0.0283 & 0.0251 \\
\hline \multirow{8}{*}{$\begin{array}{c}\text { Innovation } \\
\text { performance } \\
(\mathrm{A} 3,0.5)\end{array}$} & \multirow{8}{*}{$\begin{array}{l}\text { Social effect } \\
(\mathrm{B} 32,0.191)\end{array}$} & $\mathrm{C} 17$ & 0.065 & 0.0358 & 0.0504 \\
\hline & & $\mathrm{C} 18$ & 0.072 & 0.0445 & 0.0583 \\
\hline & & C19 & 0.036 & 0.0209 & 0.0285 \\
\hline & & $\mathrm{C} 20$ & 0.033 & 0.0411 & 0.037 \\
\hline & & $\mathrm{C} 21$ & 0.018 & 0.07 & 0.044 \\
\hline & & $\mathrm{C} 22$ & 0.021 & 0.0373 & 0.0291 \\
\hline & & $\mathrm{C} 23$ & 0.043 & 0.0495 & 0.0463 \\
\hline & & $\mathrm{C} 24$ & 0.031 & 0.0953 & 0.0632 \\
\hline
\end{tabular}

Note: the values in brackets of primary and secondary indexes are weights. 
indicator, we can get $e_{j}=-k \sum_{i=1}^{n} p_{i j} \ln p_{i j}$. The weights of the indicators are calculated according to the difference coefficient of the J-TH indicator, as shown in the fifth column of Table 2.

Third, comprehensively use the knowledge and experience of AHP experts and the objectivity of the entropy method to assign the index weights of the NASTP in Jiangxi Province. The linear combination weight formula is as follows: $w_{j}=\left(a_{1} \times w_{1 j}\right)+\left(a_{2} \times w_{2 j}\right)$, where $0<a_{i}<1$, and $a_{1}+a_{2}=1$. Among them, $a_{1}, a_{2}$ representing the weight of the two types of weighting methods, respectively. After measuring the case where the subjective weight and the objective weight in this account for an equal proportion, the results are more stable. The results are shown in column 6 of Table 2.

It can be seen from Table 2 that the weights of innovation support, innovation level and innovation performance in the first level indicators are 0.34, 0.16 and 0.5 respectively, indicating that innovation performance plays the most important role in improving the innovation ability. The innovation capacity of the National Agricultural Science and Technology Park of Jiangxi Province has achieved initial results. Among the secondary indicators, the financial support level, research and development capacity and economic benefits are respectively $0.163,0.166$, and 0.231 , which are important indicators reflecting the park's innovation capability. Among the three indicators, the top five are the number of intellectual property acquired in the year, Incubate the number of graduate enterprises, the number of patents granted, the number of new plants, animals, birds and aquatic products approved by the provincial level, the ratio of technical income and sales of production materials to annual gross output value.

\subsection{Analysis of the Innovation Ability of NASTP in Jiangxi Province}

According to the evaluation model, the comprehensive evaluation results of the innovation capability of the National Agricultural Science and Technology Park of Jiangxi Province are shown in Table 3. As can be seen from Table 3, in general, the innovation capacity of the NASTP in Jiangxi Province is quite different, and the average innovation capacity index of the park is only 0.1294 , which is at a relatively low level. The variation coefficient of innovation capacity of all parks is as high as $73.86 \%$, among which the highest innovation index of Shangrao Park is 0.2677 , followed by Jing Gangshan Park with 0.1031. The Shangrao Park

Table 3. Evaluation results of innovation ability of NASTP in Jiangxi Province.

\begin{tabular}{ccccc}
\hline Park & $\begin{array}{c}\text { Innovation } \\
\text { support }\end{array}$ & $\begin{array}{c}\text { Level of } \\
\text { innovation }\end{array}$ & $\begin{array}{c}\text { Innovation } \\
\text { performance }\end{array}$ & Creativity \\
\hline Nanchang & 0.5868 & 0.4905 & 0.1671 & 0.0992 \\
Jing Gangshan & 0.314 & 0.0224 & 0.2054 & 0.1031 \\
Xinyu & 0.0145 & 0.1721 & 0.095 & 0.0477 \\
Shangrao & 0.0847 & 0.315 & 0.5325 & 0.2677 \\
\hline
\end{tabular}


with the highest innovation capability index is 5.59 times that of Xinyu Park with the lowest innovation capability index.

From the perspective of innovation support and innovation level, Nanchang National Agricultural Science and Technology Park is at a relatively high level, but its innovation performance is not high, resulting in its low innovation ability. On the contrary, Shangrao National Science and Technology Park has a low level of innovation support and innovation, but its innovation performance is relatively high, so the innovation ability is relatively high. The possible reason is that compared to the Nanchang National Science and Technology Park, Shangrao National Science and Technology Park was established under the new background of rapid development of information and computer technology. Shangrao National Science and Technology Park relies on key projects such as the Smart Agriculture Center, the Agricultural Creator Center, the Core Area Road Network, and the Yungu Pastoral Ecological Agriculture Town, which accelerating the overall construction progress of the park, as far as possible to achieve the "curve overtaking", forming a situation that transcends the similar parks.

\section{Problems in the Innovation Ability of NASTP in Jiangxi Province}

\subsection{Unbalanced Development and Uneven Construction Level}

The four NASTP in Jiangxi Province have problems of extremely unbalanced development and uneven construction levels. For example, in terms of economic benefits, Xinyu Park has a little profit, with only 13.6 million RMB in annual tax and 16.9 million RMB in annual net profit respectively, while Shangrao Park has 9.99 times and 7.62 times of Xinyu Park respectively. In terms of informatization construction, Shangrao Park, which has the most information investment with a total investment of 3.5 million RMB, while Nanchang Park is only 40,000 RMB. This may be because Shangrao Park is a newly approved park in 2013, which needs to purchase more information infrastructure equipment. There is also a big gap in the construction of e-commerce platforms. There are 7 e-commerce platforms in Nanchang Park, while no e-commerce platform in Xinyu Park.

\subsection{Poor Hatching Ability, "Hematopoietic" Function Is Weak}

The business incubation and brand cultivation functions of the park are not strong. In 2014, the average number of incubating enterprises, graduated enterprises and newly-incubated enterprises in 106 parks nationwide were 10.9, 4.67 and 3.24 respectively. In 2016, the average number of incubated enterprises, graduated enterprises and newly-incubated enterprises in Jiangxi Province were 8.5, 2.25 and 2.25 respectively, which was far lower than the average level of 118 NASTP approved by the first five batches.

The total number of located enterprises in the Jiangxi Provincial Park was 386, which the brands was 15 in 2014. In 2016, the total number of located enterprises was 146 , where the brands was 97 . The average number of located enterprises 
and brands in each park was 36.5 and 24.25 respectively. Although the number of brands has increased significantly, the number of located enterprises in the park has decreased, far below the national average of 70.23. The total number of brands in Nanchang and Jing Gangshan Parks accounted for $83.5 \%$ of the total number of brands in the four major parks.

\subsection{Industry-Driven, Innovative Radiation Functions Has Still Not Been Fully Highlighted}

The larger the proportion of the technological income, the sales income of production materials in the total output value of enterprises, and the proportion of the second and third industry value in the total output value of enterprises in the park, the stronger the industrial driving capacity of the park, and the more obvious the growth of the industrial chain. Some enterprises in the park are still at the end of the industrial chain, staying at the planting level, to a certain extent, "replacing farmers" rather than "driving farmers". In 2016, the technical income and sales income of production materials of the four parks totaled 105.723 million RMB, accounting for only $26.17 \%$ of the annual GDP, which was lower than the national average indicating that the Jiangxi Provincial Park is mainly on the production of terminal consumer agricultural products, and the industrial driving capacity needs to be improved.

Some enterprises have a low degree of industrialization. It is impossible to establish a cooperation model of "company + base + farmer" with neighboring farmers to develop order farming, only for self-sufficient in the park. In 2016, the total output value of the secondary and tertiary industries in the park accounted for $48.05 \%$ of the total output value, far below the national average of $74.81 \%$. The industrial structure of the park still needs to be further optimized. Meantime, the park's scientific and technological innovation has limited support for economic and social development. The average number of rural households employed by each park in Jiangxi Province was 9645.5, which is far lower than the national average of 51,500. The per capita net income of farmers in the park is $18,100 \mathrm{RMB}$, which is also lower than the national average.

\section{Strategies for Improving the Innovation Ability of NASTP in Jiangxi Province}

In order to give full play to the agricultural characteristics of the park and promote the development of regional agricultural economy, it is necessary to select appropriate innovation paths according to local conditions.

\subsection{Enhance the Collaborative Innovation Capability of Agricultural Science and Technology in the Park}

Collaborative innovation in agricultural science and technology is an important part of the major strategy of coordinated development in Jiangxi Province. There are obvious imbalances and heterogeneity in the innovation capabilities of the 
various parks in Jiangxi Province, which lays a good foundation for promoting the formation of innovative developments with complementary advantages and mutual benefit.

According to the agricultural science and technology resources of the National Agricultural Science and Technology Park of Jiangxi Province, the cooperative innovation of science and technology in the fields of seed seedling industry, modern logistics and freshness preservation industry of agricultural products, facility planting industry, healthy breeding of livestock and poultry industry and urban leisure and sightseeing agriculture is mainly carried out. We should give full play to the scientific and technological advantages of agricultural scientific research institutions, optimize the allocation of existing agricultural scientific and technological resources, promote the intensification of agricultural scientific research, and realize the co-construction and sharing of scientific research resources.

In addition, according to the regional and industrial characteristics of Jiangxi province, increase financial input and comprehensively apply the technologies related to the agricultural Internet of things, the agricultural science and technology network and the agricultural recycling network to build a modernized information service platform for the agricultural science and technology park. Through informatization, the park can timely understand and master the domestic and foreign market demand, provide high-quality information services for farmers and enterprises in the park, and promote the common development of various parks in Jiangxi Province.

\subsection{Improve Business Incubation and Brand Cultivation Capabilities in the Park}

At present, the enterprise incubation construction and brand cultivation of the NASTP in Jiangxi Province are still lagging behind. The construction of modern agricultural science and technology parks should take advantage of existing infrastructure and policies of the park to promote the enterprise incubation and the cultivation of brands in the park of Jiangxi Province.

First, agricultural technology incubators should be developed to provide a broader development space for incubators. The agricultural technology incubator can provide all-round in-depth services to the park enterprises, participating in the management of the incubating enterprises, and continuously inject funds into the technology enterprises through the establishment of "start-up funds" and "seed funds" to further reduce the cost of entrepreneurship and entrepreneurial risks, which promoting the process of agricultural high-tech industrialization. At the same time, the National Agricultural Science and Technology Park should also focus on creating a good atmosphere for innovation and entrepreneurship, and build a group of innovative and entrepreneurial incubation platforms with complete functions and open sharing. On the establishment of the incubation platform, it is necessary to strengthen cooperation with large enterprises such as Alibaba, Tencent, Microsoft and other large internet companies to 
promote the development of traditional innovation platforms towards intellectualization, technology and efficiency.

Second, promote the brand building and quality management of the park to meet the diversified, personalized and high-end needs of the public. We should speed up the establishment and improvement of the agricultural standardization system with special features in the park, take the development of green and organic food as the direction of standardization, and guide leading enterprises to establish brand awareness and increase brand investment. It is necessary for us to explore agricultural science and technology parks that conform to the characteristics of regional protection of their original production, implement intellectual property protection of agricultural products in their original production areas, actively declare agricultural products for geographical indications, and create brands of featured products. At the same time, we will create a special market for green agricultural products in Jiangxi, and build a trace of quality system. We will carry out brand promotion and promotion activities in various ways, strengthen the connection between production and sales, increase brand awareness, and make the brand an effective way for enhancing the value of the park products.

\subsection{Enhance the Revenue-Driven and Innovative Demonstration Driving Effect of the Park}

The NASTP in Jiangxi Province are weak in driving ability. We should combine the policies and opportunities of local governments, make overall use of various advanced elements and transform them into real productive forces, promote the upgrading of the agricultural industrial structure in the park, and drive the construction of new rural areas around the country. In the end, it will promote the prosperity of farmers and the development of agricultural productivity.

The first is to strengthen agricultural science and technology innovation. Science and technology is crucial to the development of agricultural parks, and the only way for agricultural development is technological innovation. It is an inevitable trend to improve the quality and economic benefits of agricultural products in agricultural science and technology parks through modern science and technology. A special product technology chain should be constructed to support and extend the industrial chain of the park products.

The second is to strengthen education and training for farmers. We will carry out modern agricultural technology training and professional farmers training so that farmers can learn and master relevant professional knowledge, operational skills and management methods of agricultural facilities, improve their ability and competitiveness in the labor market, and increase their income.

The third is to establish different demonstration driving mechanisms. The results transformation and technical service mode of "experts + enterprises + bases + farmers" have been explored in Tianjin and Baise Parks, which effectively improving agricultural efficiency and farmers' income, and achieved obvious social and economic benefits. Jiangxi Province can combine its own local characteris- 
tics and use different modes such as "company + park + farmers", "scientific research institutions + parks + farmers" to enhance industry-driven and income-driven capabilities.

\section{Conclusion}

In summary, National Agricultural Science and Technology Park has played a very important role in raising farmers' income, promoting agricultural technology promotion, and promoting the integration of urban and rural areas. Practice has been proved that only by the actual situation of the location, the development of agricultural production can be achieved by adopting an innovative model based on local conditions, so that the development of the park can be taken to a new level.

\section{Acknowledgements}

This article is supported by the Science and technology project of Jiangxi Provincial Education Commission, "Study on the Combining efficiency of agricultural science and technology with finance in Jiangxi" (Project No.GJJ151514) and the Humanities and Social Sciences project of Universities in Jiangxi Province, "Study on Jiangxi's Energy Efficiency and Its Spatio-temporal Variation Based on DEA-ESDA" (Project No.JC162015) and the Graduate Innovation Special Fund Project in 2016 of Jiangxi Province, "Study on traditional Chinese medicine industry international competitiveness compared with Japanese kampo medicine industry" (Project No.YC2016-B050).

\section{Conflicts of Interest}

The authors declare no conflicts of interest regarding the publication of this paper.

\section{References}

[1] Ministry of Science and Technology, Ministry of Agriculture, Ministry of Water Resources, State Forestry Administration, China Academy of Sciences, Agricultural Bank of China (2018) National Agriculture Science Park Development Plan (2018-2025). National Science Faculty.

[2] Ministry of Science and Technology of the People's Republic of China (2015) National Key Park Innovation Monitoring Report 2014. Science and Technology Literature Publishing House, Beijing.

[3] National Agricultural Science and Technology Park Innovation Capability Evaluation Group (2017) National Agricultural Science and Technology Park Innovation Capability Evaluation Report 2015. Science and Technology Daily, 3 February 2017.

[4] Jiang, H.P. and Cui, K. (2009) Agricultural Science and Technology Park: Achievements, Models and Demonstration Focus. Issues in Agricultural Economy, No. 1, 9-14.

[5] Zhang, C.H. (2012) Exploring and Researching on the Innovative Development Model of Modern Agricultural Science and Technology Parks. Guangdong Agricultural Sciences, 39, 224-226. 
[6] Sun, H.Y., Liu, X.J. and Ju, Z.Q. (2016) Discussion on the Development Model of National Agricultural Science and Technology Park in Cangzhou, Hebei Province. Chinese Journal of Eco-Agriculture, 24, 1145-1150.

[7] Shao, H. (2012) National Agricultural Science and Technology Park Planning Research-Taking Shandong Binzhou National Agricultural Science and Technology Park as an Example. Urban Planning Journal, No. 4, 73-78.

[8] Zhou, J., Lin, A.H. and Yao, L.T. (2016) Analysis of the Effectiveness and Development Model of the Construction of Agricultural Science and Technology Parks in Xinyu. Jiangxi Science, 34, 880-890.

[9] He, W. (2007) Comprehensive Benefit Evaluation of Input and Output of Agricultural Science and Technology Park Based on DEA Method. Statistics \& Decision, No. 24, 154-156.

[10] Zhao, L.M. and Yan, Y.L. (2014) Improving the Industrial Agglomeration Effect Estimation under the CES Model-An Empirical Study Based on the National Agricultural Science and Technology Park in Xuchang, Henan Province. Agricultural Economy, No. 11, 78-80.

[11] Xu, C.Q. (2016) Analysis of Land Use Efficiency in the Core Area of National Agricultural Science and Technology Park. Journal of China Agricultural University, No. 12, 108-113.

[12] Shen, X.Q. and Xiu, C.B. (2012) Drawing on Foreign Experiences to Develop China's Agricultural Science and Technology Parks. Research on Modern Economy, No. 11, 78-81.

[13] Song, Y.P. and Li, J. (2018) Evaluation of Radiation Driving Capacity of National Agricultural Science and Technology Park. Journal of Shandong Agricultural University, Social Science Edition, No. 1, 47-53.

[14] Zhou, H.Q., Zou, Y.X., Liu, C.Z., Feng, W.S. and Wang, J.D. (2018) Innovation Research on Evaluation Index System of Agricultural Science and Technology Park: Functional Perspective. Science \& Technology Progress and Policy, No. 3, 140-148.

[15] Etzkowitz, H. (2004) The Evolution of the Entrepreneurial University International. Journal of Technology and Global Isolation, No. 3, 18-28.

[16] Xu, Y. (2004) Exploring the Development of Agricultural Science and Technology Parks by Trying to Integrate Innovation Theory. Journal of Agrotechnical, 2, 2-9.

[17] Zhou, L. (2010) Analysis of the Sources of Innovation Capability of Modern Agricultural Science and Technology Parks-Based on the Comprehensive Framework of Knowledge, Learning and Social Capital. Guangdong Agricultural Sciences, 37, 271-273.

[18] Luo, G., Sun, J. and Xiao, T. (2016) Study on the Development Trend and Innovation Ability of the National Agricultural Science and Technology Park in Guangdong Province. Science and Technology Management Research, No. 23, 108-114.

[19] Xia, Y. and Li, D. (2017) Evaluation on Innovation Capability of Agricultural Science and Technology Parks Based on Analytic Hierarchy Process-Take Anhui for Example. Journal of West Anhui University, No. 10, 54-60.

[20] Ministry of Science and Technology of the People's Republic of China (2017) National Key Park Innovation Monitoring Report 2016. Science and Technology Literature Publishing House, Beijing. 